\title{
ALTERATIONS OF CERVICAL VERTEBRAE IN TWO INDIVIDUALS FROM THE LATE ANTIQUTY NECROPOLIS FROM THE "BIG MOUND" NEAR CABYLE, BULGARIA
}

\author{
Victoria Russeva \\ Institute of Experimental Morphology, \\ Pathology and Anthropology with the Museum, \\ Bulgarian Academy of Sciences, Sofia, Bulgaria
}

\begin{abstract}
The anthropological examination of two skeletons, of individuals identified as males, at 30-40 and 60-65 years, respectively, excavated from the grave complexes of the Necropolis of Big Mound, Cabyle, dated in the late $4^{\text {th }}$ century $\mathrm{AD}$, revealed abnormalities in the cervical section of the vertebral column, in $\mathrm{C} 1^{\text {st }}$ and $2^{\text {nd }}$. In the first case (grave $\mathrm{N} 2$,), neural arches of $\mathrm{C} 1$ and $\mathrm{C} 2$ are fused together by two clearly visible bony bridges at the dorsal side of neural arches. In the second case (grave N 3) both vertebrae are changed, with the dens axis strongly bended to the left, the articulation surfaces with the first vertebra are on different geometrical surfaces, the left one being on a higher position and bended at approximately $90^{\circ}$. The form the first cervical vertebra is adequate to the changes of the second vertebra. A lack of lesions, characteristic of the trauma or the infection is observed. The case from grave N 2 appears easy to be explained with inborn anomaly, as the Clippel-Fiel syndrome. The appearance of fusion, realized by clearly distinguishable bony bridges and clearly divided vertebrae from each other, instead of characteristic of the inborn condition, close, undivided position of neural arches with unclear outlines, the result from abnormality in embryonic development makes it also possible to have the interpretation as a survived trauma in the region. The changes of cervical vertebrae from the individual from grave $\mathrm{N} 3$, could be interpreted as the development in the course of ossification of the centre of the dens axis and these both as halves of atlas during infancy.
\end{abstract}

Key words: C1-C2 abnormalities, Late Antiquity, Bulgaria 


\section{INTRODUCTION}

The necropolis, having series of graves, excavated on the "Big Mound" near the ancient town of Cabyle, after the researchers of the archeological site [8] had left, is dated in the late $4^{\text {th }}$ century AD. The excavations uncovered nine graves, containing more complete skeletons presenting bones in situ in anatomical order from whole/part of the skeleton [8] from eight individuals. There were found also traces from disturbed graves, including many single fragments from human bones from the fill of graves or from the terrain.

\section{MATERIAL AND METHODS}

For the anthropological identification of skeletal remains were used the methods, described in Acsádi \& Némeskeri [1] for the gender determination after the assessment of features on pelvic and cranial bones, with the priority of data from pelvic bones. For the inclusion of more information were used also the measurements of long bones as diameters of femoral, humeral and radial heads, the bicondylar breadth of femora and humeri and the length of clavicle compared to the tables of Pearson and Thieme in Bass [3], Kühl [4], and Alekseev [6]. The age at death of the adult individuals was assessed according to the methods for scoring the pubic bone symphyseal surface relief following Todd in Schwartz [5] and the cranial suture closure following Simpson-Olivier in Alekseev-Debets [7].

In the material five males, two in the age group of adults, 20-40 years at death, two matures, 40-60 years, one senile, of 60-65 years and four females, two in the age group of adults, 20-40 years and two matures, 40-60 years were recognized. After single fragments were determined, the remains of more than 19 individuals, from which more than nine children in the age group Infants I, 0-7 years of age, and ten individuals with finished skeletal development, over 18-20 years of age.

In the anthropological examination of two skeletons from the grave complexes, dated in the late $4^{\text {th }}$ century $\mathrm{AD}$, were found abnormalities in the cervical section of the vertebral column. In the first case, the individual from grave $\mathrm{N} 2$, square $\mathrm{J} /-1$, neural arches of two cervical vertebrae are fused together (Figure 1: 1-3). The fragments are identified as the posterior arch and the right lateral mass of $\mathrm{C} 1$ and the respective posterior arch and the right lateral mass of $\mathrm{C} 2$, fused dorsally 
with two bony bridges. The bridges between the affected vertebrae develop from the inside of the arches and are clearly divided and defined. The excavated material did not present the whole cervical section of the vertebral column, but from a fragment it appears that the following C3 shows a developed bony reaction from arthritis on the right superior articular facet, correspondent to similar changes on the right inferior articular facet of the C2 (Figure 1: 4-5).

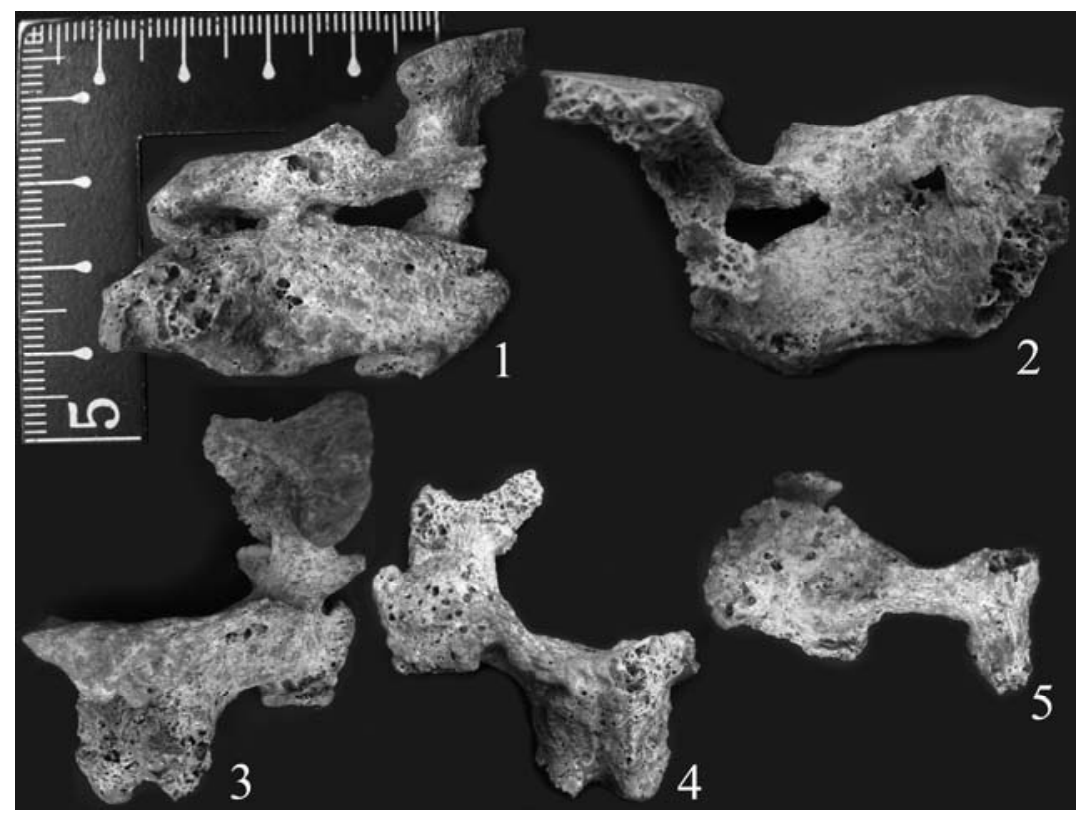

Figure 1. Grave N 2, square $\mathrm{J} /-1$, the Big Mound, Cabyle. Fragments from $\mathrm{C} 1-\mathrm{C} 3$. 1. Fragment from $\mathrm{C} 1-\mathrm{C} 2$ posterior view. 2. Fragment from $\mathrm{C} 1-\mathrm{C} 2$, view from the vertebral foramen. 3. Fragment from $\mathrm{C} 1-\mathrm{C} 2$ proximal view. 4. Fragment from $\mathrm{C} 1-\mathrm{C} 2$ distal view. 5. Fragment, lateral right proximal articular surface of $\mathrm{C} 3$. 


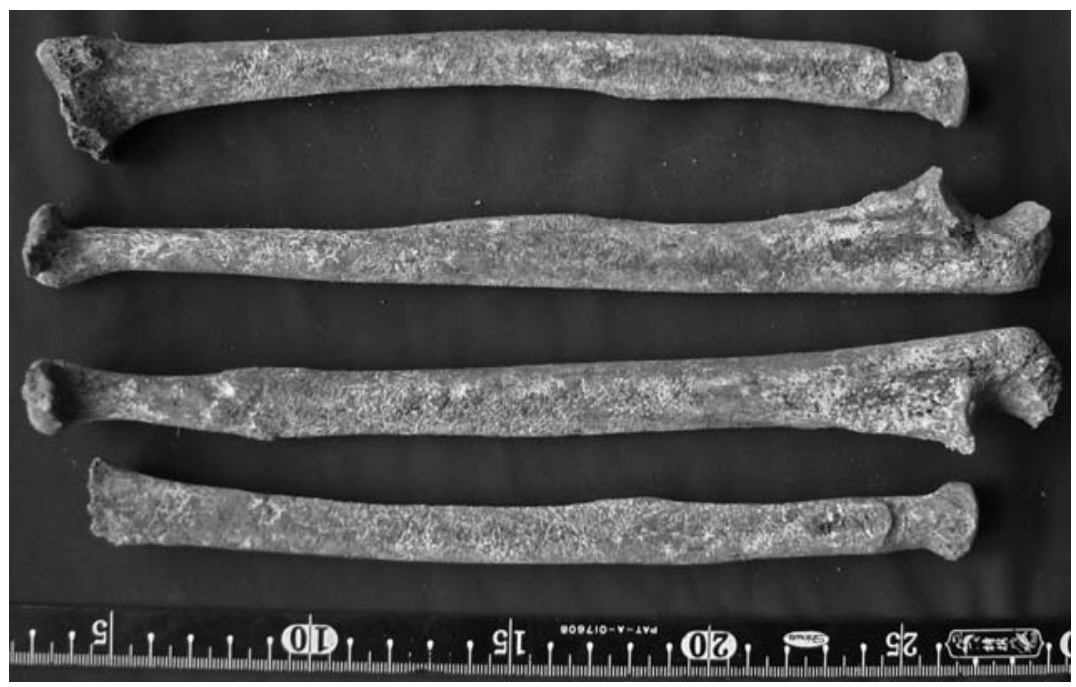

Figure 2. Grave N 2, square $\mathrm{J} /-1$, the Big Mound, Cabyle. Radiuses and ulnae.

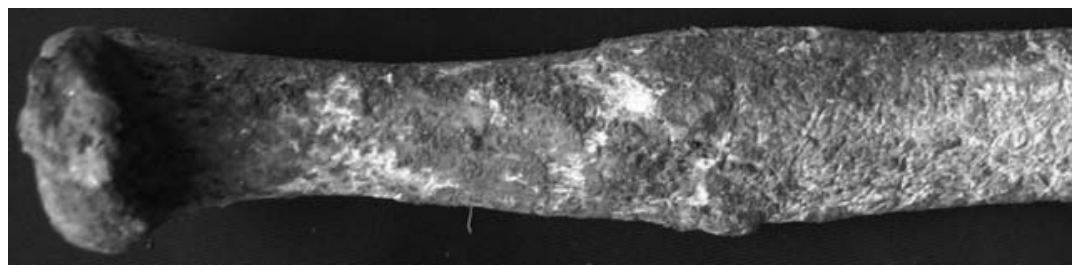

Figure 3. Grave N 2, square J/-1, the Big Mound, Cabyle. Detail, distal part of radius with traces of trauma. 


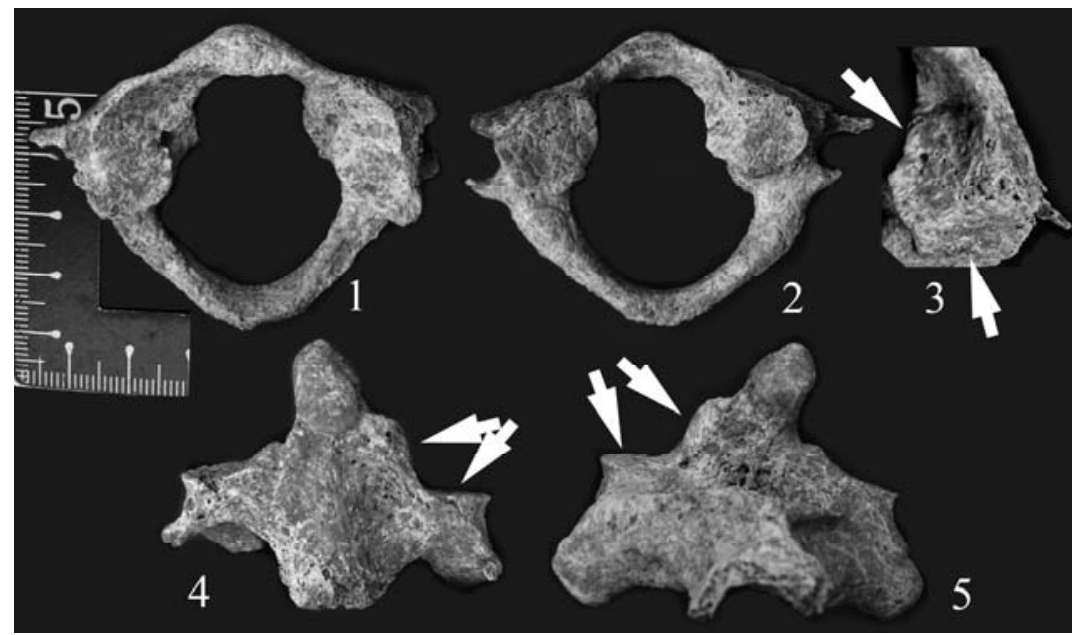

Figure 4. Grave N 3, square $\mathrm{J} / \mathrm{-1}$, the Big Mound, Cabyle. 1. C1 proximal view. 2. $\mathrm{C} 1$ distal view. 3. Detail, the left inferior articulation surface of $\mathrm{C} 1$ arrows to surfaces of changed articulation facet. 4. C2 anterior view, arrows to the surfaces of the changed articulation facet. 5. C2 posterior view, arrows to the surfaces of the changed articulation facet.

The skeletal material from the individual found in grave $\mathrm{N} 2$, square $\mathrm{J} /-1$ was highly destructed and incomplete. The skull was presented with fragments from the cranial vault, including the frontal bone, with the supraorbital region, the fragments from both parietals, from the occipital bone (from the squama and the basilar part), fragments from both temporal bones. From the face skeleton both zygomatic bones and the fragment from the right part of maxilla were present. Mandible allowed reconstruction. Dentition was fragmentarily preserved. From the bones of the postcranial skeleton both humeral bones, radiuses, ulnae and the right clavicle were complete or fragmentarily presented accompanied with the incomplete number of carpals, metacarpals and phalanges of hands. From both scapulae only fragments, both presenting glenoid fossa and acromion were found. From the vertebral column four cervical and four thoracic vertebrae were found. A fragment from the manubrium of sternum was also present.

With no preserved pelvic bones, the gender of the individual from grave $\mathrm{N} 2$ square $\mathrm{J} / \mathrm{-1}$ was ascertained as a male after the descriptive 
features of the cranial fragments as the moderately developed relief of glabella region, the oval shaped superior orbital margin, the developed temporal relief over the external auditory meatus and on the mastoid processes and massiveness and the relief of mandible were fixed. The values of the vertical diameter of the humeral head and the bicondilar breadth were more close to the mean for the male gender after the used tables. After the cranial sutures obliteration, the age of this individual was estimated 60-65 years, the age group of senile. Fragments from dentition showed advanced teeth loss - ascertained at least one incisor, two premolars and five molars lost ante mortem. Alveolar processes show the traces from the advanced periodontal disease. The bones from upper limbs and the vertebral column showed advanced degenerative changes on the articulation surfaces. On the material from this individual the presence of a trauma lesion on the distal third part of the diaphysis of the left ulna was found (Figures 2,3). The correspondent part of the left radius was not affected from a trauma, but suffered from the advanced arthrosis in the wrist joint (Figure 2).

The second case of the abnormal anatomical form of the cervical vertebrae was registered on $\mathrm{C} 1$ and $\mathrm{C} 2$ of the individual from grave $\mathrm{N} 3$, square $\mathrm{J} / \mathrm{-}-1$. In this skeleton the dens axis of $\mathrm{C} 2$ is strongly bended to the left, the vertebral body appears changed from the normal anatomical form. Its articulation surfaces with $\mathrm{C} 1$ lie in different geometrical surfaces, a part of the left one being bended at approximately $90^{\circ}$ with one surface remaining with proximal orientation, on a higher position and the other part, perpendicular, with the lateral orientation, the right lateral articulation surface, respectively, remains on a lower position (Figure 4: 4-5). The form of the $\mathrm{C} 1$ is adequate to the changes of the $\mathrm{C} 2$, being bended according to the uneven positions of the articulation surfaces of the vertebral body of the second vertebra (Figure 4: 1-3). Its left distal articulation surface shows the form respective to the geometry of the articulation of the C2 (Figure 4:3). On both, C1 and C2 are not ascertained lesions, which can be interpreted as traces from the fracture or the infectious process, neither posttraumatic nor from general infection. The articulation between the dens axis and the atlas suffered from strong degenerative changes, pronounced on both bones. In this case the $\mathrm{C} 3$ and $\mathrm{C} 4$ are present and do not show changes, including the signs for the development of the degenerative joint disease.

The skeletal material from the individual from grave $\mathrm{N} \mathrm{3}$, square $\mathrm{J} /-1$ was preserved in a better condition. Again, the skull was fragmentary 
with parts from the frontal bone, with the supraorbital region, fragments from both parietal and temporal bones and the occipital squama. From the face both zygomatic bones and fragments from the alveolar processes of maxilla and mandible with partially preserved dentition were present. The postcranial skeleton was represented by both humeral bones, radiuses, ulnae, femurs, the right tibia and the left clavicle were fragmentarily presented accompanied with the incomplete number of carpals, metacarpals, tarsals, metatarsals and the phalanges of hands and feet. From both scapulae only fragments with preserved glenoid fossa and acromion were found, from pelvic bones fragments, including both pubic bones were found, on both pelvic bones a greater sciatic foramen is preserved. From the vertebral column four cervical, 11 thoracic and all five lumbar vertebrae were found. A big portion of sacrum was also preserved, allowing the reconstruction of the form and dimensions. Numerous fragments of ribs were also present.

During the anthropological examination the gender of this individual was ascertained as a male, after some features of the observed pelvic fragments, as the form of a greater sciatic foramen and the reconstructed pubic angle. Some of the observed features on cranial fragments, as the developed relief of the glabella region, the developed relief of supraorbital arches, the oval form of the upper margin of both orbits, the developed temporal relief over the external auditory meatus, the lateral tubercle of both zygomatic bones, the massive mandible, with the developed relief on the angle led to this identification. Characteristic of the male gender were the taken measurements of the bones of limbs. The age at death of this individual was estimated 30-40 years after the obliteration of cranial sutures. The relief of the pubic bones and the auricular surfaces on the iliac bones was difficult for accurate assessment, because of its post mortal destruction, but it appeared as a characteristic for the determined age. Dentition of this individual was with one fragmentarily preserved incisor, two canines, five premolars and eight molars. From the present teeth, the upper second left molar was affected by caries, the reduced alveolar process and the shallow alveolus on the place of the lost upper right first molar pointed to its destruction from the carious process and even the loss shortly ante mortem. Alveolar processes showed the traces of the periodontal disease. A line of enamel hypoplasia could be correlated to the second year of individual development. On orbits the lack or cribra orbitalia 
was ascertained. On lumbar vertebrae changes caused by spondylosis were observed. Traces from initial arthrosis were found on both glenoid fossae, on humeral trochlea at both sides and on the olecranon of both ulnae.

\section{RESULTS AND DISCUSSION}

Both finds present controversial aspects of interpretation. The case from grave $\mathrm{N} 2$, square $\mathrm{J} /-1$ appears easy to be explained with inborn anomaly of the vertebral column, as the Clippel-Fiel syndrome. Embarrassing in this interpretation is the appearance of fusion, realized by bony bridges, clearly visible and distinguishable from each other and from neural arches, clearly divided as well from each other, instead of the characteristic for the inborn condition close, undivided position of the fused parts of bones as a result of the failure of formation of fissures between them in the development as described by Barnes [2]. Possible explanation of the abnormality in this case could be as well a survived trauma in the cervical section of the vertebral column. A trauma, observed on the left ulna can not be related with the changes in cervical vertebrae, but could be regarded as a circumstantial evidence for the risks in the life of this individual.

The cervical vertebrae from the individual from grave $\mathrm{N} 3$, square $\mathrm{J} /$ 1 showing no lesions, which can be undoubtedly interpreted as traumatic, or bone reaction characteristic of infectious condition, do not show abnormality, registered on the anthropological material as an inborn condition as well. The changes, visible on the find, could be interpreted as developed in the course of ossification of the posterior arch and the lateral masses of $\mathrm{C} 1$ and the ossification of dens axis, the body and the dorsal arch of C2 during infancy, from the early stage of the process, with fusing of the arch and the body of $\mathrm{C} 2$ at 3 years, the simultaneous ossification of the posterior arch of $\mathrm{C} 1$ between 3-4 years and the fusion of the anterior arch of $\mathrm{C} 1$ with the lateral masses at 5-9 years as described in Swartz [5]. The normal ossification of C1 and C2 could have been disturbed by a trauma, and the survival of the individual at that age. It could also have been caused by a specific activity, which could have overloaded the section of the vertebral column disturbing the normal morphology of $\mathrm{C} 1-\mathrm{C} 2$. 
Both findings from the cervical section of both individuals could be regarded as a result from conditions during infancy of specific hazards of everyday life of the population or the specific activity of individuals at that age. The rest of the skeletons of the series, which are poorly preserved, did not show such changes in the cervical section of the vertebral column or traces of trauma.

\section{REFERENCES}

1. Acsádi G., Nemeskéri J. (1970). History of Human Life Span and Mortality. Budapest, Akademiai Kiado, 333.

2. Barnes E. (2008). Congenital anomalies. In: ed. Pinhasi, R., Mays, S., Advances in Human Paleopathology. Willy \& Sons, 329-362.

3. Bass W. (1971). Human Osteology: a Laboratory and Field Manual of the Human Skeleton. University of Missury, 281.

4. Kühl R. (1985). Skelettreste aus prähistorische Brandbestattungen und ihre Aussagemöglichkeiten, mit Hinweisen auf spezielle Fragestellungen in Schleswig-Holstein. Mitteilungen der Anthropologischen Gesellschaft in Wien (MAGW), Band 115, 113-137.

5. Schwartz J. H. (1995). Skelleton Keys (An Introduction to Human Skelletal Morphology, Development and Analysis). New York, Oxford Press, 362.

6. Алексеев В. (1966). Остеометрия, методика антропологических исследований. Москва, Наука, 252 с.

7. Алексеев В., Дебец Г. (1964). Краниометрия, методика антропологических исследований. Москва, Наука, 228 с.

8. Стоянов Т., Р. Миков Т. Джанфезова (2010). № 59. Спасително археологическо проучване на обект 7 - надгробна могила и околомогилното й пространство и сондажи по корекцията на трасето на шосето с. Кабиле - с. Жельо войвода. АОР за 2009 г., 239-243. София.

\section{Address for correspondence}

Victoria Russeva

Institute of Experimental Morphology,

Pathology and Anthropology with the Museum,

Bulgarian Academy of Sciences, Sofia, Bulgaria

E-mail: victoria_russeva@yahoo.com 